\title{
FDA faces legal challenge over failure to disclose data on antibiotic resistance
}

$\mathrm{D}$ o "trade secrets" trump the public interest in containing antibiotic resistance associated with extensive farmyard use of such drugs to promote growth in the meat and poultry industries?

That question lies at the core of a legal challenge launched in the United States District Court of Columbia in December 2012 in which the Washington, DC-based Government Accountability Project (GAP) is accusing the US Food and Drug Administration (FDA) of breaching freedom of information law for failing to release data on antibiotic drug usage.

The application for injunctive relief contends that the FDA wrongfully refused to disclose information to scientists at the Johns Hopkins Center for a Livable Future (an academic research centre based at the Johns Hopkins Bloomberg School of Public Health in Baltimore, Maryland) on the grounds that it should withhold privileged trade secrets.

GAP's brief argues that the scientists were seeking "aggregated data concerning the amount of antimicrobial active ingredient being sold for each class of antimicrobial drugs, rather than data concerning sales or distribution by each individual sponsor, broken down by container size, strength, dosage form, and class of animal" (www.whistle blower.org/storage/documents/Complaint _120512.pdf).

As such, there would have been no breach of corporate confidentiality if the information had been released, the complaint adds. "Disclosure of the information sought by GAP is not likely to cause substantial harm to the competitive position of any manufacturers of drugs containing the antimicrobial active ingredients to which the information pertains."

According to GAP, nearly 30 million pounds of antibiotics - or $80 \%$ of all antibiotics sold in the US - are utilized by the meat industry. Under the

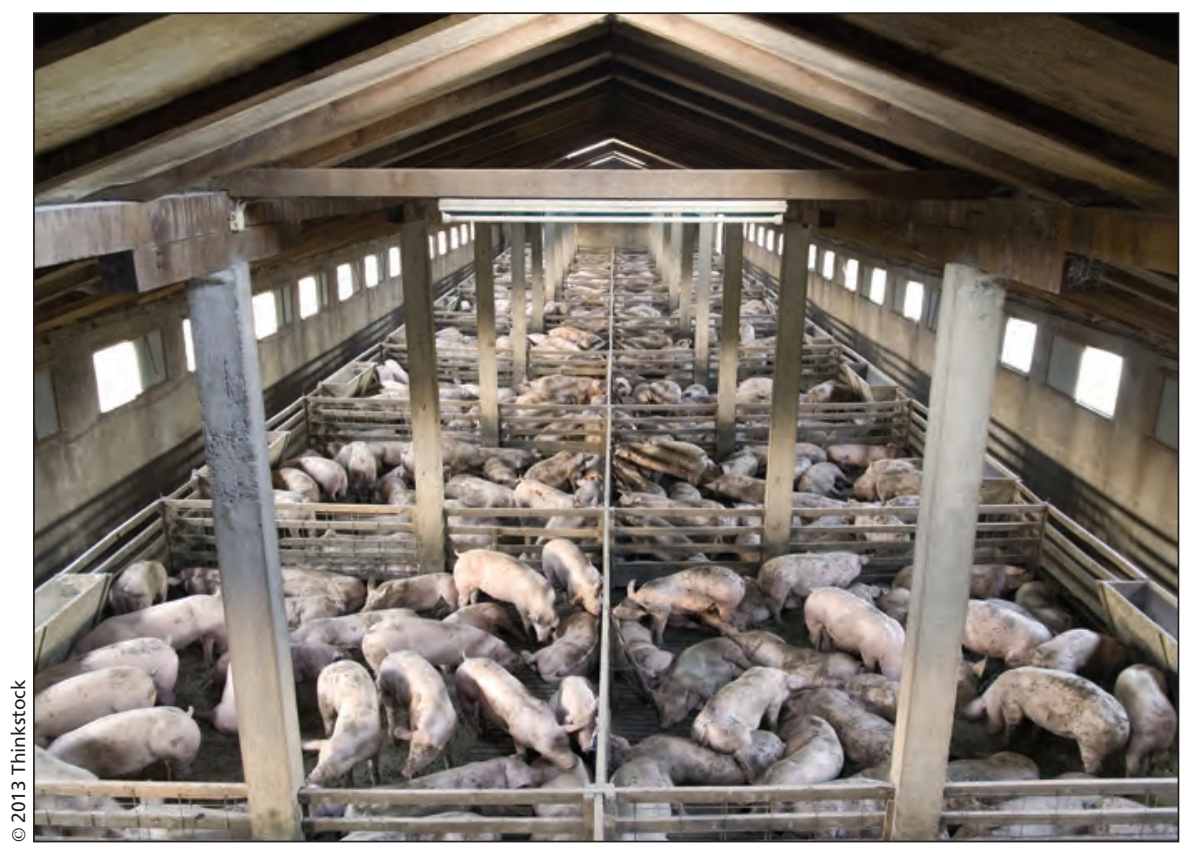

The Government Accountability Project estimates that $80 \%$ of all antibiotics sold in the United States are utilized by the meat industry.

US Animal Drug User Fee Act, drug companies are required to report to the FDA how much of each drug is sold, how the drugs are formulated, and which animals these drugs are approved for. FDA publicly releases a limited summary of that data but withholds almost all information reported by companies.

The FDA's failure to disclose the information demonstrates a bias toward hiding industry practices, argues Amanda Hitt, food integrity campaign director for GAP. "The agency's job is to protect the public's health, not industry secrets," she says. "If we can't even access basic information about the volume and type of specific drugs industry uses, how can we truly know the extent to which these drugs are causing harm?"

FDA, which is currently conducting public consultations on improving antibiotic data collection and dissemination, has not yet responded to GAP's legal claim, which comes in the wake a recent court ruling that found its actions were "arbitrary and capricious and otherwise not in accordance with the law" in denying citizen petitions for a full evaluation of the safety of farm use of antibiotics on the grounds that doing so would be "too time consuming and resource intensive" (www.louise.house .gov/images/stories/Order_on_Petitions _Claim.pdf).

Data about antimicrobial use on farms are collected by nations such as Denmark to determine the mean and extent of usage and to identify farmers who are utilizing antibiotics at a level well above the norm.

But there is no need for public disclosure of such information, argues Morgan Scott, a veterinary epidemiologist at Kansas State University in Manhattan, Kansas. "I have almost zero sympathy for those who seek to publish the data at levels that identify the drug company, farmer, or veterinarian as there can be little defensible or useful purpose for doing so," he says. "My guess is the FDA cannot release the 
data in the granular nature the FOI [freedom of information] requests because each 'cut' or categorization beyond 'class of antimicrobial' makes it easier to identify the company involved. Did the FDA err on the side of caution in interpreting what it could release? Most probably."

Canadian observers say that the FDA's refusal to disclose antibiotic usage data collected from meat and poultry producers, and the debate over the extent of trade secrecy, resembles the stance taken by the Canadian Food Inspection Agency.

The Canadian agency collects antibiotic usage information at abattoirs but does not publicly disclose that data, a situation that officials with the Public Health Agency of Canada and Health Canada have challenged (www.cmaj.ca /lookup/doi/10.1503/cmaj.109-4055).

"In the last couple of years we've been encouraged that antimicrobial resistance issues are more broadly understood and of higher profile," says Lynora Saxinger, chair of the Canada Antimicrobial Stewardship and Resistance Committee. "But it is profoundly disappointing that data apparently being collected isn't being used to help us fill in knowledge gaps we are all aware of."

Canadian officials also say that data collection will improve north of the 49th parallel commencing last month with the launch of a new surveillance program that will be managed in partnership between farmers and the Public Health Agency of Canada's Canadian Integrated Program for Antimicrobial Resistance Surveillance (CIPARS).

To be implemented in four provinces, it will "monitor any usage and resistance levels at the farm and provide us with a great deal more information. The results will be reported in the regular CIPARS annual reports. We believe that this is an important step in providing third-party credibility," says Lisa Bishop-Spencer, manager of communications at the Chicken Farmers of Canada. - Paul Christopher Webster, Toronto, Ont.

CMAJ 2013. DOI:10.1503/cmaj.109-4381 